\title{
A revised agricultural drought index in Lithuania
}

\author{
Egidijus Rimkus, Viktorija Maciulyte, Edvinas Stonevicius and Donatas Valiukas \\ Institute of Geosciences, Vilnius University, Čiurlionio 21, LT-03101 Vilnius, Lithuania \\ e-mail: egidijus.rimkus@gf.vu.It
}

\begin{abstract}
The objective of this study was to develop the best methodology for determining agricultural droughts in Lithuania. The currently used assessment methods do not always accurately reflect drought conditions in the country, especially in the first half of the growing season. For this purpose, the relevance of the currently used Hydrothermal Coefficient (HTC) and five drought indices widely used in other countries were reassessed. It was found that the methodologies applied in Lithuania and other countries are not completely suitable under current conditions. A new agricultural drought identification methodology using the Temperature-Precipitation Index (TPI) is proposed as a result of this study. Analysis of long-term changes (1961-2019) in reoccurrence of droughts was carried out. It was determined that the largest number of droughts in Lithuania was recorded in the last decade of the 20th century and in the first decade of the 21st century. Despite the fact that there is a positive tendency in reoccurrence of droughts, the changes are not statistically significant.
\end{abstract}

Key words: droughts, Temperature-Precipitation index, soil moisture, growing season

\section{Introduction}

Drought is the most dangerous natural phenomenon in terms of frequency, extent and magnitude of impact. It has a significant impact on various areas: agriculture (Li et al. 2009), natural vegetation (Vicente-Serrano et al. 2010), water resources (Bond et al. 2008), hydropower (Naumann et al. 2015), forest fires, etc. Drought is different from other dangerous meteorological phenomena because it is slowly forming and long-lasting.

The concept of drought is not the same in different regions. Therefore, the definition of this phenomenon will vary considerably between arid and humid climates. Various drought indices are used to monitor drought formation and impact. Like most phenomena, drought is characterized by strength, spatial extent and duration. The duration of the majority of natural phenomena is limited to the duration of the phenomenon itself, while the effects of drought are experienced even after it has ended (Niemeyer 2008, Naumann et al. 2015, WMO \& GWP 2016). In most cases, drought indices are categorized according to the impact they are associated with. Meteorological, agricultural and hydrological as well as socioeconomic droughts can be distinguished (Wilhite and Glantz 1985, Zargar et al. 2011). The existence of several major types of drought demonstrates that there is no single method to evaluate all types of these phenomena. Even when assessing each type of drought individually, it is not always clear which index is most suitable (Keyantash and Dracup 2004). In most cases, drought is identified when the index value exceeds a certain threshold value, i.e. the established drought criterion is reached. In some cases, a drought is declared when that criterion persists for a defined period of time. It should also be emphasized that drought is a social phenomenon and should not be judged only by meteorological indicators but by the impact on the social environment as well (Wilhite and Glantz 1985).

Drought indices often identify the duration, severity and spatial extent of droughts in different ways. A comparison of the ten most commonly used drought indices found weak to moderate correlations between precipitationbased indices for identification of meteorological droughts. Soil moisture-based indices for agricultural drought showed even weaker correlations, while indices for the identification of hydrological drought showed the strongest relationship (Wanders et al. 2017). Meteorological drought indices often capture neither agricultural nor hydrological droughts (Wanders et al. 2017). It is particularly difficult to choose the most appropriate indicator for the assessment of agricultural drought, since its accuracy depends on the type of crop, farming practices, irrigation systems, etc. Therefore, universal drought indices require reference to water supply, demand and management (Lloyd-Hughes 2014). Thus, in order to determine the most suitable drought indicator, the analysis should be region-specific (Quiring and Papakryiakou 2003). As early as 1985, Wilhite and Glantz stated that 'there cannot (and should not) be a universal definition of drought'. 


\section{AGRICULTURAL AND FOOD SCIENCE}

E. Rimkus et al. (2020) 29: 359-371

Drought indices calculated from satellite data are distinguished as a separate category, although most of them are used for the identification of agricultural drought (Dalezios et al. 2012). Satellite data for drought monitoring are used not only to assess vegetation status, but also to identify soil moisture anomalies. A strong relationship between vegetation status and soil moisture profile would allow prediction of growing conditions without the need for complex physical models or a large-scale satellite database (Zribi et al. 2010). It would also allow assessment of the vegetation response to rainfall and soil moisture (Jamali et al. 2011).

Previous analysis of drought dynamics in Lithuania showed that there were no clear signs that the number of extreme droughts had increased while there was an increase in Standardized Precipitation Index (SPI) values in some sub-basins of the Neman river (Rimkus et al. 2013). Such tendencies have been also found over a large part of the Baltic Sea region (Rimkus et al. 2012). Future projections (2081-2100) show that it is likely that the climate in the Neman river basin will become more humid in April and May and drier between June and August (Stonevicius et al. 2018). Another study sought to determine the impact of droughts on plant growing conditions in the eastern part of the Baltic region using satellite Normalized Difference Vegetation Index (NDVI) and Vegetation Condition Index (VCI). It was found that NDVI cannot be used universally to identify droughts, but it may be applied to better assess the effect of droughts on vegetation (Rimkus et al. 2017).

The aim of the study is to propose an updated methodology for the detection of extreme agricultural droughts in Lithuania. For this purpose, analysis of drought indices and their suitability to the climatic conditions of Lithuania was carried out. Currently, in Lithuania, meteorological droughts are identified using SPI, while the Hydrothermal Coefficient (HTC) index is used to identify agricultural droughts. The HTC index has a number of shortcomings that prevent drought from being identified and declared even though agriculture is suffering from the impact of drought. Failure to identify drought according to the officially used drought index makes it difficult to declare an emergency at country or municipality level. Not only do the farmers lose their harvest, they also have no access to financial support.

At the first part of the results section we discuss the suitability of various widely used drought indices for drought identification in Lithuania. The following sections compare the currently used HTC with our proposed TPI (Temperature-precipitation index) and evaluate the dynamic of the number of droughts according to these indices. The effect of drought on yields is discussed at the end of the results section.

\section{Material and methods}

We used daily meteorological measurement data in 1961-2019 from the Lithuanian Hydrometeorological Service station network. Data from 18 meteorological stations (MS) with the longest observation series were used in this research (Fig. 1). Only Dukstas MS started operating in 1971. The following meteorological indicators were used for drought assessment: average daily air temperature $\left({ }^{\circ} \mathrm{C}\right)$, minimum and maximum air temperature $\left({ }^{\circ} \mathrm{C}\right)$, and daily precipitation amount $(\mathrm{mm})$.

For the purpose of developing the most suitable methodology for determining agricultural droughts in Lithuania, five widely used drought detection indices as well as currently used HTC and our proposed TPI were selected for analysis.

HTC (Hydrothermal Selianinov coefficient) (Selyaninov 1928) - an official drought indicator in Lithuania (1).

(1) $H T C=\frac{P}{0.1 \sum T}$,

where $P$ is the sum of the 30-day precipitation in $\mathrm{mm}$, and $\Sigma T$ is the sum of the average daily temperature over the same period (when daily average air temperature is above $10^{\circ} \mathrm{C}$ ). Drought can be declared when HTC is below 0.5 for 30 consecutive days.

SPI (Standardized Precipitation Index) (McKee et al. 1993) is standardized drought index calculated by applying a gamma distribution to a long-term precipitation series, which later is transformed into a standard normal distribution. Only precipitation amount is used for SPI calculation. Interpretation of SPI values are shown in Table 1. 


\section{AGRICULTURAL AND FOOD SCIENCE}

E. Rimkus et al. (2020) 29: 359-371

\begin{tabular}{lc}
\multicolumn{2}{l}{ Table 1. SPI, SPEI and EDI interpretation (WMO 2012) } \\
\hline Interpretation & Value \\
\hline Extremely wet & $\geq 2.0$ \\
Very wet & $1.99-1.5$ \\
Moderately wet & $1,49-1.0$ \\
Near normal & $0.99--0.99$ \\
Moderately dry & $-1--1.49$ \\
Severely dry & $-1.5--1.99$ \\
Extremely dry & $\leq-2.0$ \\
\hline
\end{tabular}

SPEI (Standardized Precipitation Evapotranspiration Index) (Vicente-Serrano et al. 2010) is standardized drought index which use precipitation and PET (potential evapotranspiration) data. In this study, PET was calculated by the Hargreaves method (Hargreaves and Allen 2003) using daily minimum and maximum air temperatures.

The calculated PET is used to estimate the difference (D) between precipitation (P) and evapotranspiration (Hargreaves and Allen 2003) (2).

(2) $\quad D=P-P E T$

Further the SPEI is calculated similarly to the SPI, just only the long-term sequence of difference $D$ is used instead of the long-term precipitation series and a log-logistic distribution is applied. Interpretation of SPEI values is the same as SPI (Table 1).

EDI (Effective Drought Index) (Byun and Wilhite 1999) is standardized drought index which use only precipitation data. EDI is calculated by estimating the effective precipitation EP (3), where $i$-duration of the period (days), $P m$ - precipitation amount $(\mathrm{mm}) \mathrm{m}$ days before date.

(3) $E P_{i}=\sum_{i}^{n=1}\left[\frac{\sum_{n}^{m=1} P_{m}}{n}\right]$

EDI is standardized value of EP. Interpretation of EDI are shown in Table 1.

PNP (Percent of Normal Precipitation) is one of the simplest indices for calculating precipitation anomalies. This index is based on the ratio of precipitation amount $(\mathrm{mm})$ for a given analysis period $(\mathrm{Pi})$ to the average long-term precipitation amount $\left(\mathrm{P}_{\text {mean }}\right)$ for the same period (4).

(4) $P N P=\frac{P_{i}}{P_{\text {mean }}} \times 100$

Extreme drought is recorded when PNP $<50$.

Al (Aridity Index) (WMO \& GWP 2016) is aridity index which is calculated as a ratio of precipitation (P) and potential evapotranspiration (PET) (5).

(5) $I=\frac{P_{i}}{P E T_{i}}$

Drought can be declared when $\mathrm{Al}<0.2$.

TPI (Temperature-Precipitation Index) is our proposed index (6), where $\mathrm{P}$ is the precipitation sum of the previous 30 days $(\mathrm{mm})$, and $\mathrm{T}$ is the sum of the daily average air temperature $\left({ }^{\circ} \mathrm{C}\right)$ during the same period.

(6) $T P I=\frac{P}{T} \times 100$ 


\section{AGRICULTURAL AND FOOD SCIENCE}

E. Rimkus et al. (2020) 29: 359-371

The calculation of TPI starts when the 30-day average air temperature is above $5{ }^{\circ} \mathrm{C}$. Officially, a drought should be declared when the average TPI value for the 30 previous days is below 3.5. In order to calculate the duration of a drought, 29 days used to calculate the average value of TPI on the first day of the drought should be added to the number of drought days. The extreme drought ends when the TPI value falls below 3.5. The possibility of using another criterion (TPI < 3.0) for extreme drought identification has been also considered.

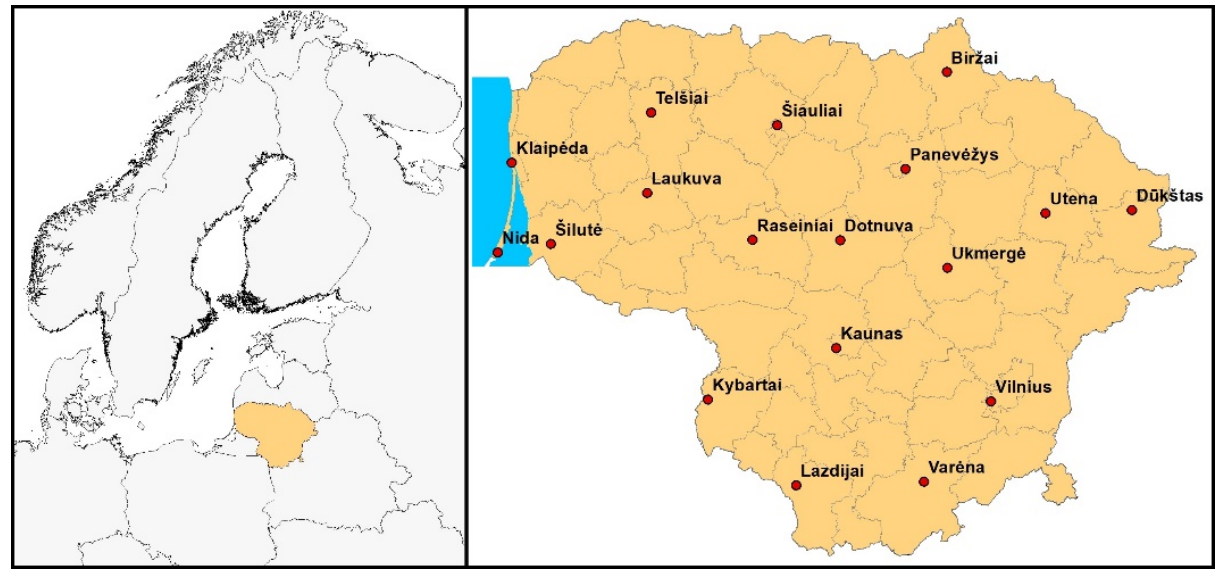

Fig. 1. Location of meteorological stations whose data were used in this study

During index selection, attention was paid to the fact that the parameters needed for index calculation should be densely measured in Lithuania in order to reflect as much as possible the spatial extent of the droughts.

We also used soil water content data from 1970 to 1999 as a direct indicator of soil condition. Observations of soil water content in Lithuania started in the second half of the 20th century. Measurements were made by gravimetric method, i.e. soil samples from various depths were weighed before and after drying. In 2000, such observations were terminated. In 2009, soil water measurements were renewed, but soil water potential started to be measured. The quality of measurements is not satisfactory and even the soil type as well as its profile are not described at the monitoring sites. There are a number of gaps in the measurements, and the current monitoring sites are in many cases different from previous ones. Besides that, the relationship between soil water content and water potential is very specific for each soil (Dexter 2004).

For this reason, we examined soil water content $(\mathrm{mm})$ data at three MS (Kaunas, Šilutè and Biržai) during the period from 1970 to 1999. Soil water content was measured every 10 days in April-October by gravimetric method (up to $1 \mathrm{~m}$ depth).

The possibility of assessing the impact of droughts using crop yield data was also evaluated. These data were obtained from the data archive of Statistics Lithuania. We analysed cereal crop yield (t ha ${ }^{-1}$ per year) in Biržai, Kaunas and Šilutè municipalities from 2000 to 2019. Cereals are the most cultivated agricultural crops in Lithuania. The yield data show a positive trend, which is related to changing agricultural practices and increasing crop yields due to the cultivation of new, more productive species of agricultural crops. For the purpose of evaluating the impact of droughts, the data were detrended by subtracting expected values according to linear trend from the observed values.

Air temperature and precipitation data were standardized for the purpose to assess the magnitude of the anomalies. The strength of the relationships between the variables was evaluated using Pearson linear correlation coefficient. A nonparametric Mann-Kendal test was used to assess the statistical significance of the trends. Both correlation coefficients and trend values were considered statistically significant at $p<0.05$. 


\section{AGRICULTURAL AND FOOD SCIENCE}

\section{Results \\ Selection of the most appropriate drought index for Lithuania}

Distribution of precipitation, air temperature and PET deviations during different soil moisture $(0-20 \mathrm{~cm})$ periods was evaluated for the purpose of determining which meteorological parameters are the most important and should be included in drought index calculation (Fig. 2).

The analysis of results show that soil moisture is lower during the period with precipitation deficit. During the spring and in August-September, the air temperature or PET is also very important in assessing droughts. When their values are above the average, the soil moisture values tend to be low and vice versa (Fig. 2). It can be concluded that it is very important to use drought indicators which include air temperature or PET data during assessment of agricultural droughts in Lithuania.
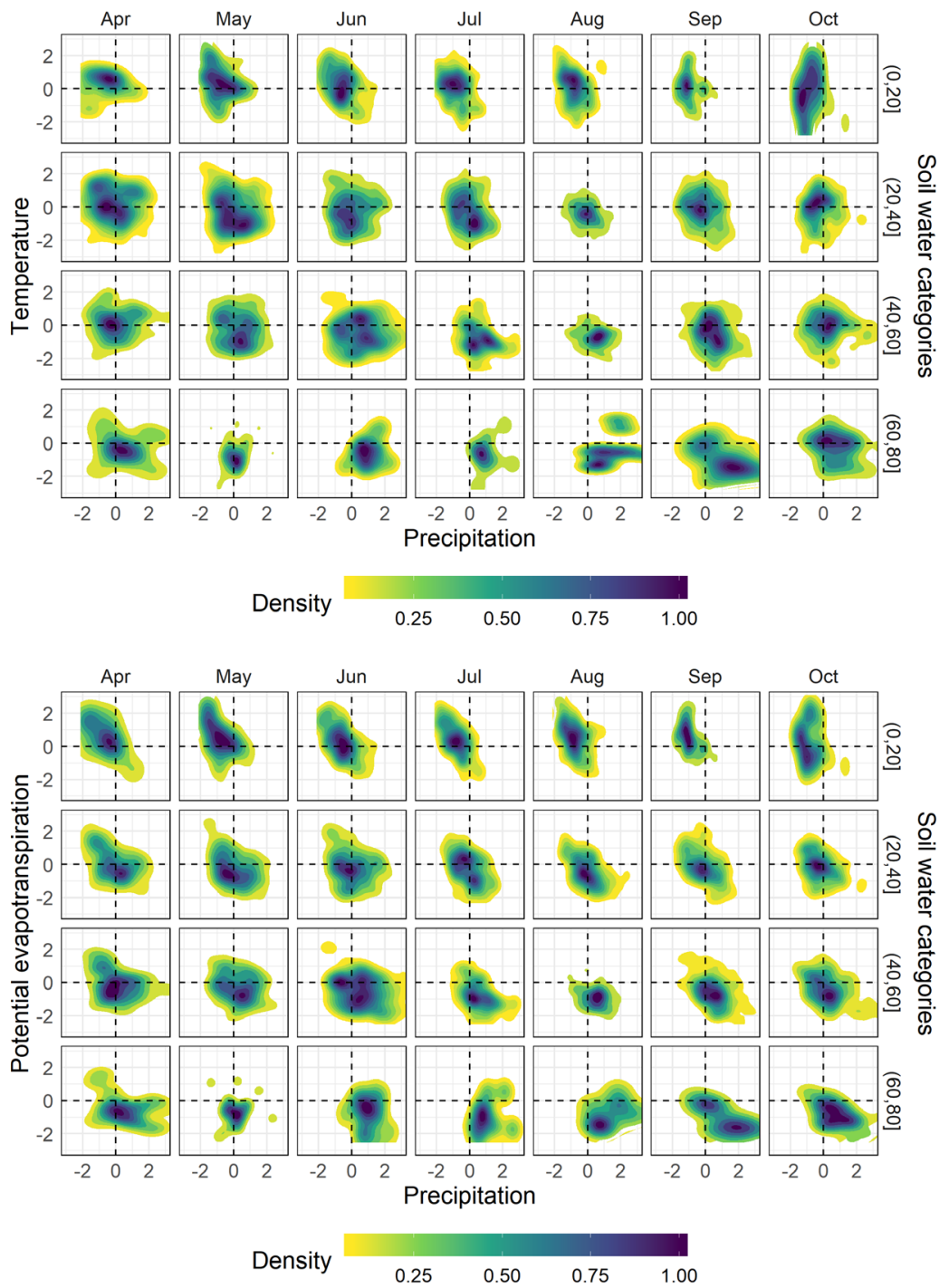

Fig. 2. Distribution of standardized 30-day precipitation amount and air temperature (above) or potential evapotranspiration (below) values during different surface $(0-20 \mathrm{~cm})$ soil water conditions $(0-20,20-40,40-60$ and $60-80 \mathrm{~mm})$. The 0 represents mean conditions, the divergence from mean is shown in standard deviations. Darker colors represent a larger reoccurrence of meteorological conditions.

The indices that use only precipitation (SPI, EDI, PNP) do not meet this criterion; therefore, they are less suitable for estimation of drought conditions in Lithuania than indices based on precipitation and temperature or evapotranspiration data. SPEI and AI are estimated using precipitation and air temperature or PET data. SPEI is a standardized index and $\mathrm{Al}$ is non-standardized. 


\section{AGRICULTURAL AND FOOD SCIENCE}

E. Rimkus et al. (2020) 29: 359-371

Standardized drought indices are suitable for describing anomalies in meteorological conditions. The values for a given period are compared with the 'normal' conditions for that area, so the probability of drought is the same everywhere. This is due to the fact that in calculating standardized values for the distribution of precipitation and PET, a log-logistic theoretical distribution is applied in the case of SPEI and subsequently transformed into a normal distribution (Beguería et al. 2014).

Applying the theoretical distribution to empirical data results in a high degree of uncertainty in the ranges of minimum (important for drought) and maximum values; therefore, normalized distributions may differ from normal distributions in different locations. In Lithuanian MS, reoccurrence of extreme droughts identified by SPEI3 values varied from $0.0 \%$ to $7.8 \%$, although according to the normal distribution it should be $2.3 \%$ (Fig. 3 ). It is important to note that these differences are determined not so much by the unevenness of the reoccurrence of dry conditions in the territory of Lithuania as by the uncertainty in mathematical calculations. The statistical limitations of standardized precipitation indices for assessing agricultural droughts have also been discussed in previous studies (Blain 2012).

The reoccurrence of droughts is likely to shift with changing climate conditions, so it is very important that the selected criterion would be able to assess this change. Standardized indices compare current conditions with 'normal' ones, so even if the climate is changing the probability of droughts will remain, e.g. the definition of normal conditions and the criteria for extremity would also change. For example, after a period of frequent droughts, the drought criterion would change, and even during a period with relatively little precipitation, the drought can be no longer declared. Standardized indices are more suitable for long term drought analysis at selected monitoring points with a long data series. However, they are much less usable for the operational identification of droughts especially if the information from newly established stations is to be used for this purpose.

Taking into account the above-mentioned features of standardized drought indices, it is more appropriate to use non-standardized drought indices such as Al, which can be linked to the absolute amount of water in the soil. Soil water content in Lithuania depends on the amount of precipitation as well as the air temperature.

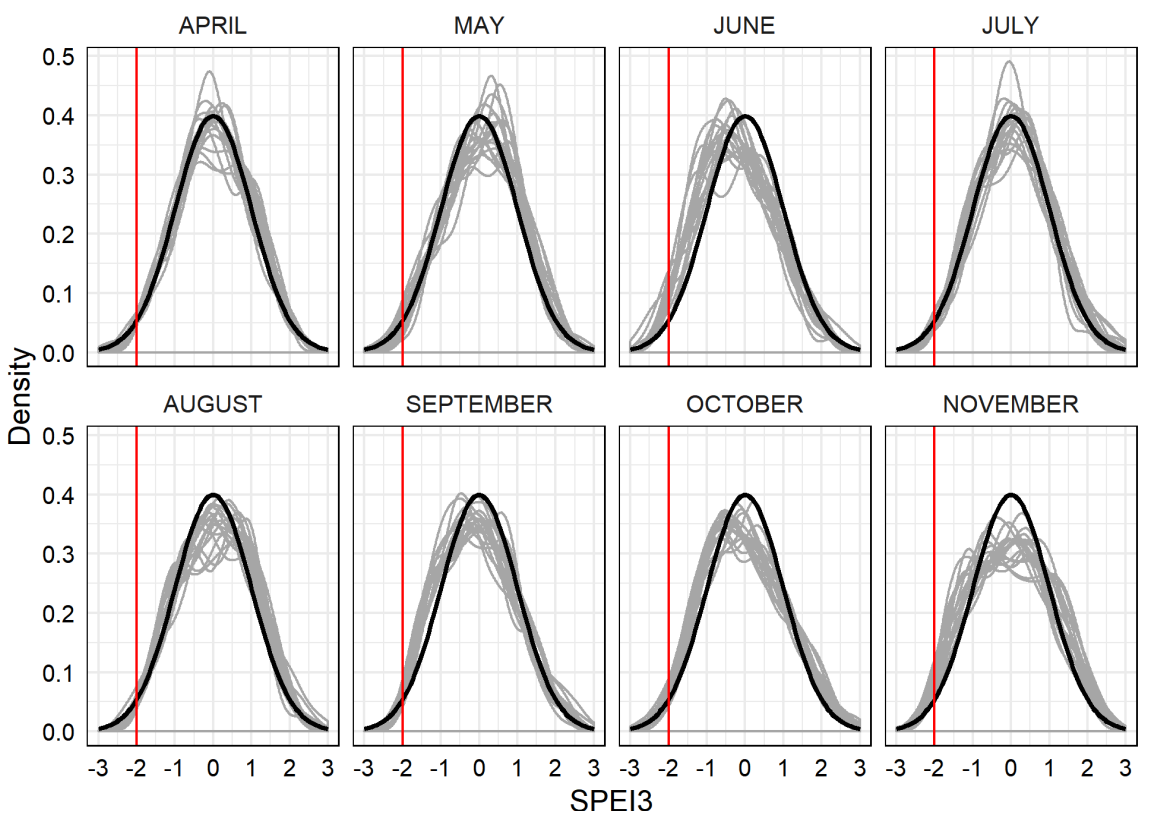

Fig. 3. Normal distribution (black line) and distribution of SPEI3 values in different months of the growing season at 18 Lithuanian meteorological stations (grey lines). The red vertical line represents the threshold below which SPEI3 values indicate extreme drought.

Precipitation and PET data were used to calculate Al. When converting air temperature to PET, its effect on Al values becomes more important than that of precipitation. The correlation of Al with average 30-day air temperature is higher than with the average 30-day amount of precipitation (Fig. 4). 


\section{AGRICULTURAL AND FOOD SCIENCE}

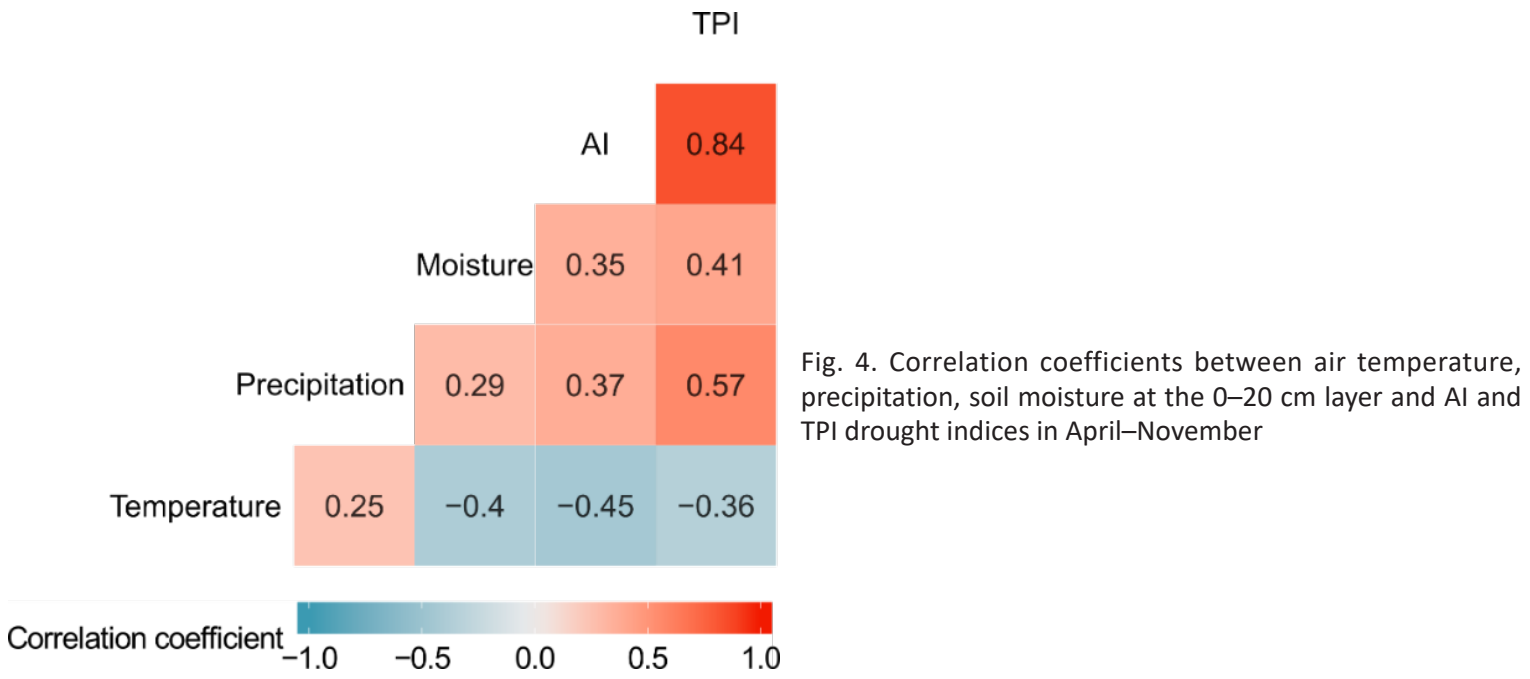

In summer, soil moisture is more dependent on precipitation amount than on air temperature, so it is important that the index used to evaluate droughts is sensitive to precipitation. This condition is satisfied by our proposed TPI, which has a correlation coefficient with precipitation higher than that of Al. The relationship of TPI to soil moisture is also closer, making TPI more appropriate than Al for evaluation of agricultural droughts in Lithuania.

\section{Selyaninov's HTC}

HTC is the only official drought index for identifying and declaring extreme agriculture drought in Lithuania. According to their extent, extreme droughts can be divided into local and nationwide events. If an extreme drought is determined at one or several weather stations, it is of local significance; if it covers a third or more of the territory of Lithuania, it is considered nationwide. However, identification of droughts according to HTC also causes some uncertainties and problems.

The HTC evaluates the hydrothermal conditions of the growing season. However, evaluating droughts only during the period when the daily average air temperature is above $10{ }^{\circ} \mathrm{C}$ does not allow the identification and assessment of droughts that occur in early spring. This problem became evident during the recent droughts in Lithuania (in 2015, 2018, 2019). In spring, a drought is usually related to high soil temperature and it can cause more damage to vegetation than low temperatures (Hossain et al. 2012).

Sometimes, two long dry periods (HTC $<0.5$ ) are separated by one or several days when the HTC is just above the threshold. In this case, a drought that lasts for almost 2 months is not declared. Short-term fluctuations in HTC may be due to light rainfall but also due to a sudden drop in temperature, although it has not been accompanied by rain.

In some years, the air temperature transition date above $10^{\circ} \mathrm{C}$ in spring months may vary by several or even more than 10 days at neighbouring weather stations. This is typical for years with low temperatures in April and May and is determined by the formal criterion for calculating such dates. As a result, the date when extreme drought can be declared in neighbouring areas can vary by more than a month, although in many cases agricultural activity is synchronized. For example, in 1977 the $10^{\circ} \mathrm{C}$ threshold in the western part of Lithuania was reached only on June 7 and in such a case, the earliest date when it is possible to declare an extreme drought would not be until August 6 (after 61 days).

Based on our research, the TPI is applied to identify extreme droughts in Lithuania. This index is based on daily measurements of precipitation and air temperature as well as HTC. However, our proposed index avoids most of the formal calculus-related drought detection problems listed above that occur with HTC and also allows identification of early spring droughts.

Snow cover during the cold season is usual for the boreal zone. Moisture accumulates in the soil as the snow melts, so only when the snow is completely melted the formation of drought can start. Plant growth starts when the average daily air temperature rises above $5{ }^{\circ} \mathrm{C}$ (Grigorieva et al. 2010). During all winters we investigated, 


\section{AGRICULTURAL AND FOOD SCIENCE}

E. Rimkus et al. (2020) 29: 359-371

the permanent snow cover had already melted when the average air temperature was higher than $5{ }^{\circ} \mathrm{C}$ for 30 consecutive days. Therefore, this threshold of average air temperature - above $5^{\circ} \mathrm{C}$ for a 30 -day period - can be used to identify droughts using TPI values. Use of a longer period of time may result in the loss of some information about early spring droughts, while during a shorter period (10 or 20 days), the snow cover may not disappear, especially after snowy winters.

In 1961-2019, the average 30-day air temperature typically reached the $5^{\circ} \mathrm{C}$ threshold in the second half of April (Fig. 5A), while it dropped below $5{ }^{\circ} \mathrm{C}$ in November (Fig. 5B). Agricultural work in Lithuania starts in April and, in most cases, an extreme drought can be declared in the second half of May, according to TPI. According to the HTC index, the earliest drought could be declared at the end of June. This was particularly important in 2019, when the agricultural sector suffered losses due to the extremely dry conditions of spring and early summer.

A)

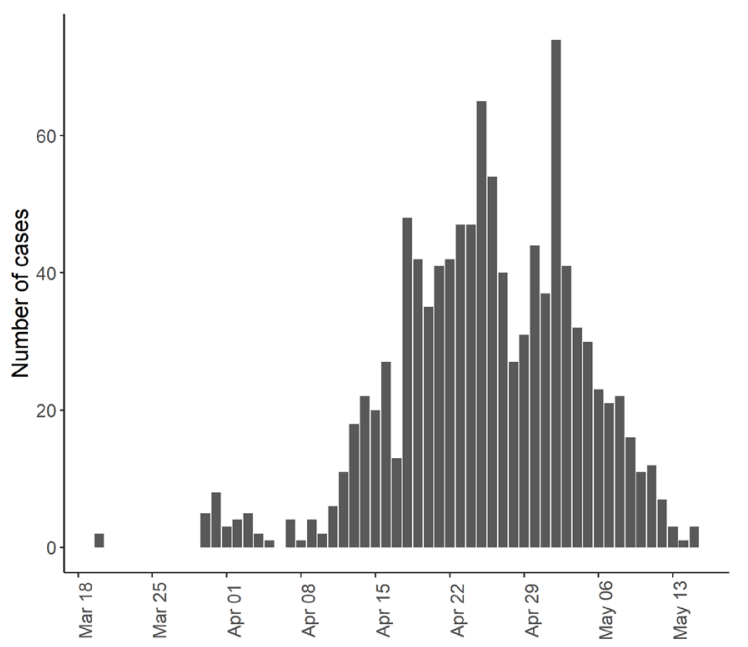

B)

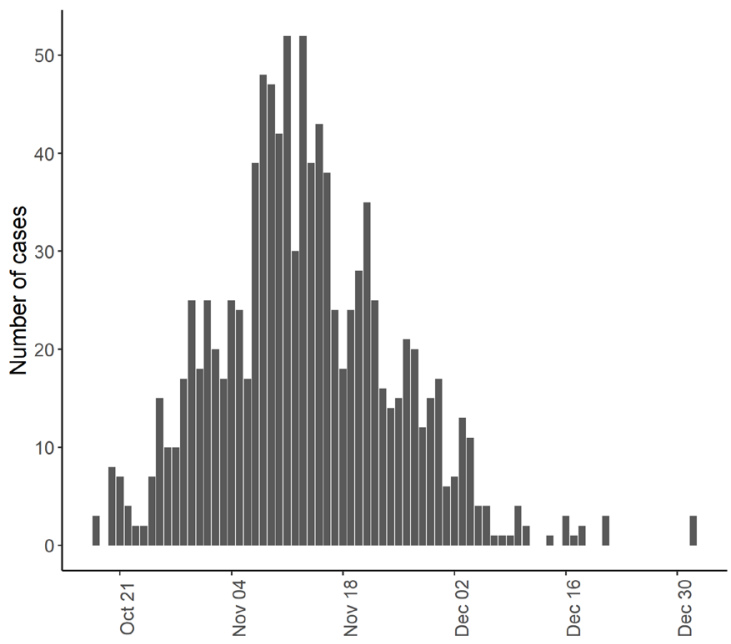

Fig. 5. Dates of 30-day average air temperature transition through $5{ }^{\circ} \mathrm{C}$ in Lithuania during spring (A) and fall (B), according to data from 18 weather stations in 1961-2019

The changes of weather conditions in Lithuania are very fast, so it is reasonable to apply a relatively short 30-day averaging period for TPI. In order to avoid the effects of short-term fluctuations in TPI values, it is proposed to use the 30-day average TPI values rather than use a certain number of consecutive days for which the calculated TPI value meets the criterion.

\section{Reoccurrence of droughts according to HTC and TPI in 1961-2019}

According to HTC, during the period 1961-2019, the number of droughts recorded in MS varies from one in the southeast (Vilnius MS) to seven on the Baltic Sea coast (Nida) (Fig. 6A). Under thresholds of TPI $<3.5$ and TPI $<3.0$, the number of droughts is higher. According to $\mathrm{TPI}<3.5$, it varies from four droughts in Vilnius to thirteen in Dotnuva and Nida (Fig. 6B), and according to TPI <3.0 from two droughts in Vilnius to ten in Dotnuva and Nida (Fig. 6C).

Evaluating the spatial distribution of droughts during the analysed period, we can notice that there are significant territorial differences in Lithuania. According to all indices, droughts are less frequently recorded in south-eastern and eastern Lithuania, and more often in western and central parts of the country.

According to HTC, there were 16 (27\%) years between 1961 and 2019 with at least one MS which recorded drought. According to TPI $<3.5$ and TPI < 3.0, there were 29 (47\%) and 22 (37\%) drought years, respectively. On average, drought at the weather station according to HTC was recorded once every 13 years, according to TPI $<3.0$ every 8 years, and according to TPI $<3.5$ every 6 years. The number of nationwide droughts which covered more than a third of the territory of Lithuania (recorded in more than six stations) is also different. According to HTC, there were four such droughts $(1992,1994,2002,2006)$, to TPI < 3.0, eight $(1992,1993,1994,1996,2000,2002,2006$, 2019) and according to TPI < 3.5, there were ten droughts (1971, 1992, 1993, 1994, 1996, 2000, 2002, 2006, 2008, 2019). The most extensive droughts were recorded by HTC in 1992 and 1994 (13 MS), by TPI < 3.0 in 2000 (17 MS) and by TPI 3.5 in 1994 and 2000 (17 MS). 


\section{AGRICULTURAL AND FOOD SCIENCE}
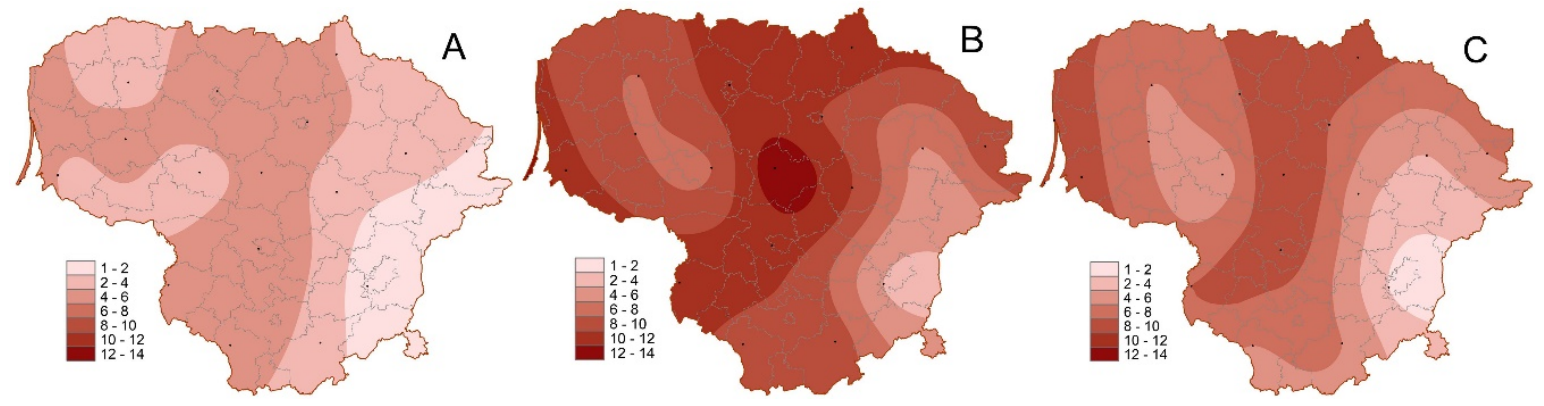

Fig. 6. Reoccurrence of extreme droughts in Lithuania in 1961-2019 according to HTC (A), TPI < 3.5 (B), TPI < 3.0 (C)

The total number of droughts at all weather stations between 1961 and 2019 according to HTC was lower than according to TPI < 3.5 or TPI < 3.0 (Fig. 7). The number of drought years according to HTC is lower mainly due to the fact that droughts were not recorded at the beginning of the growing season. It should be noted that according to all indices, most of the nationwide droughts were identified in the second half of the growing season, whereas the local droughts dominated in the first half of the growing season. There were only a few cases when drought was recorded by HTC but not recorded by TPI (Dotnuva MS in 1964; Kybartai MS in 1969; Klaipeda MS in 1992). The years 1993, 2000 and 2019 were exceptional due to fact that drought was not recorded at all by HTC (in 2019 in one MS) whereas according to TPI < 3.0 in all mentioned years the drought covered more than a third of the country and according to TPI $<3.5$ drought covered more than two-thirds of the Lithuanian territory. In all above-mentioned cases, the droughts were recorded at the beginning (1993 and 2019) or at the end (2000) of the growing season.

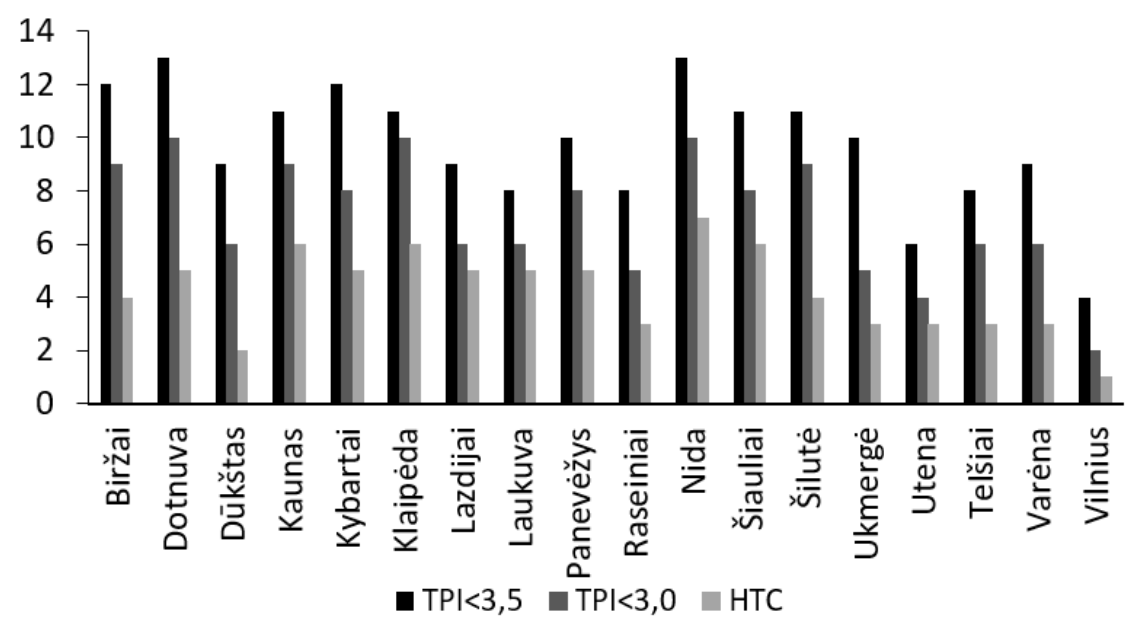

Fig. 7. Number of droughts recorded at weather stations according to $\mathrm{HTC}, \mathrm{TPI}<3.5$, and $\mathrm{TPI}<3.0$ in 1961-2019

The majority of droughts occurred between 1992 and 2006 (Fig. 8). During this period, 60-68\% of droughts were recorded according to different drought criteria. Also, droughts were recorded in many locations in 2018 and 2019. Meanwhile, the number of droughts was very low (15-25\%) in the period up to the end of 1980s. Although there is an obvious tendency for an increase in the number of droughts, there were no statistically significant changes according to the Mann-Kendal test.

\section{Effect of drought on yields}

Analysing the data for 2000-2019, it was found that years with low grain yields are not necessarily related to droughts (Fig. 9). The noticeable negative yield anomalies ( $<-0.3 \mathrm{t} \mathrm{ha}^{-1}$ ) were recorded in 2001 (Kaunas), 2006, 2007 (Silute), 2010, 2011 (Kaunas, Silute), 2013 (Birzai), 2018 and 2019 (Kaunas). Only in 2006, 2018 and 2019 yield anomalies can be attributed to droughts. In 2006, the drought was recorded by all studied indices, in 2018 by SPI, SPEI, AI, PNP and in 2019 by all indices except SPEI. The most significant drop in yields in 2006 is undoubtedly due to the drought recorded in the middle of summer. Although droughts were not recorded in the three investigated municipalities in 2018 according TPI $<3.5$, but droughts has been recorded in more than a third of the country territory. 


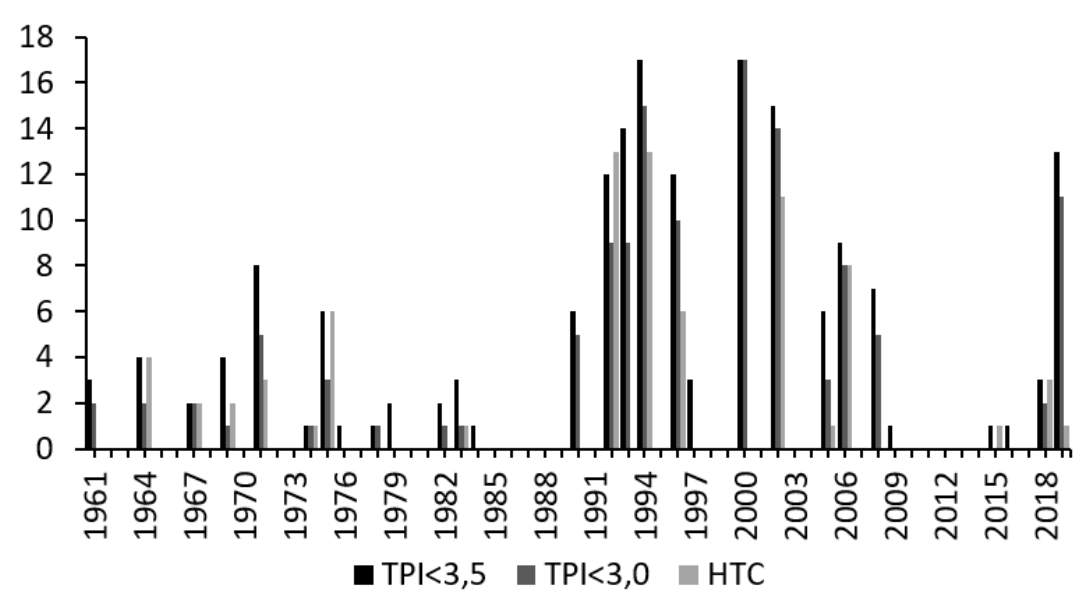

Fig. 8. Number of meteorological stations in Lithuania where droughts were recorded in 1961-2019 according to TPI $<3.5$, TPI $<3.0$ and HTC

However, droughts did not always lead to lower yields. The early droughts in at least one station recorded in the 2000 (SPI, AI), 2004 (PNP, Al), 2008 (SPI, PNP, Al, TPI), 2017 (SPI) as well as at the second half of the 2002 (all indexes), 2005 (TPI), 2015 (SPI, EDI, PNP) growing seasons did not have a big effect. Not all droughts have a negative impact, especially if they occur during harvesting. Moreover, droughts in the second half of the growing season in 2002 and 2015 could led to better harvesting conditions and higher yields. Droughts at the beginning of the vegetation period also do not necessarily determine the harvest at the end of the season. It should be noted that yields depend on many factors and drought cannot be identified using these data.

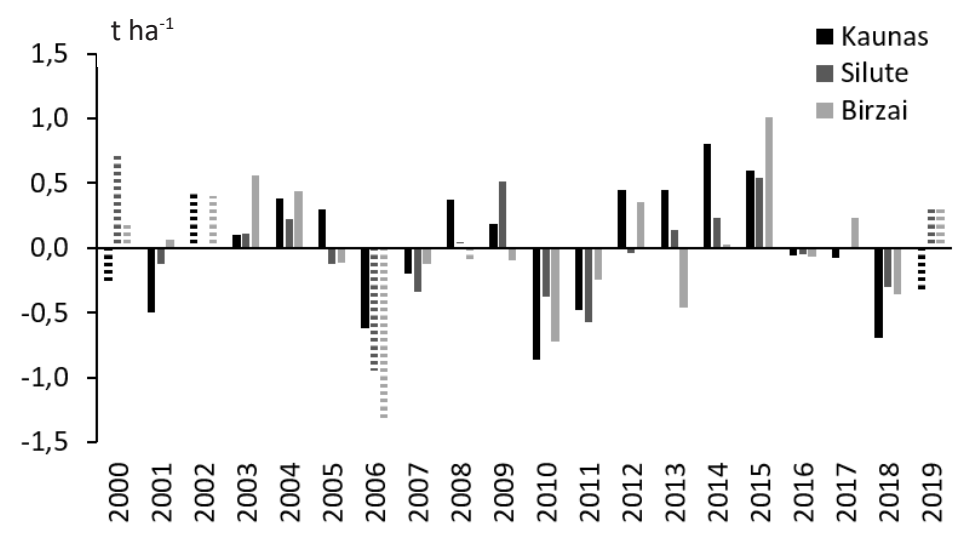

Fig. 9. Cereal yield deviation $\left(\mathrm{t} \mathrm{ha}^{-1}\right)$ from the detrended average for 2000-2019. Cases when drought has been recorded according to $\mathrm{TPI}<3.5$ in that municipality are shown as broken lines.

\section{Discussion and conclusions}

Those scientists who argue that there is no reason to seek a universal drought criterion on a global scale seem to be right (Lloyd-Hughes 2014, Wilhite and Glantz 1985). Even in one region, the interpretation of drought may vary. In neighbouring countries, the prevailing agricultures are often not the same and the irrigation system is differently developed. Even on nearby farms, the effects of drought can vary, as farmers have different water supply infrastructures. It should be noted that the damage caused by drought so far is not as great as the damage caused by a long rainy period (especially during harvesting) in Lithuania. Moreover, there are sufficient surface and groundwater water resources in the country's territory to supply agricultural crops even during the most severe drought. However, the irrigation infrastructure is underdeveloped, as the financial losses caused by droughts are not yet so significant that farmers would be interested in their construction over large areas.

None of the analysed indices showed a clear link between yield and drought. However, information about yield can be used to assess the impact of droughts. Yields depend on many factors, not only on environmental 


\section{AGRICULTURAL AND FOOD SCIENCE}

E. Rimkus et al. (2020) 29: 359-371

conditions but also on economic activity (for example proper farming). Favourable conditions before or after the drought may weaken the effects, but drought still cause's losses, which in this way become less obvious. During droughts, farmers can use certain measures, such as watering, which reduces yield losses but increases the cost of growing crops and does not eliminate the drought itself. Prompt assessment of the drought conditions shows the potential threat to the harvest and allows the necessary action to be taken. Often these actions are sufficient to mitigate the effects of droughts on yield. Therefore, an index capable of informing about an emergency without evaluation of harvest is necessary.

Our proposed methodology, which is based on TPI calculation, is also not an entirely accurate method, but it does better than the previously used HTC for identification of agricultural droughts throughout the growing period.

The choice of drought criterion, and in particular its critical values, leading to the declaration of an emergency, is a more political step that balances the interests of the Ministry of Agriculture, insurance companies and farmers, rather than a decision based on entirely objective scientific information. Scientists provide calculations but decisions are made by government structures. With the official declaration of extreme drought, farmers have access to some benefits, additional subsidies and financial support.

Probably the most accurate way to identify drought is through direct monitoring of vegetation status in a particular field. But direct measurements can be made only in a limited number of places due to their high cost and human resource demand. Another more or less accurate way of estimating agricultural droughts is through direct measurements of soil moisture (Krueger et al. 2019). However, even in this case, the identification of drought is not straightforward as the wetting moisture depends on the crops grown in the field, and the same moisture deficit will affect only certain crops. In addition, the ability of the plant root system to pump water also depends on the type of soil, i.e. the same absolute soil water content in different soils can lead to unequal effects on agricultural crops. However, extensive direct measurements of soil moisture would provide more information on soil and vegetation status than indirect calculations of drought indices based on precipitation amount and air temperature.

The evaluation of vegetation state from satellite data is also subject to considerable uncertainty and there is a lack of a reliable way to associate plant state anomalies with drought effects. The state of vegetation is affected by various meteorological factors, not just droughts. During almost all droughts, the vegetation indices (NDVI, $\mathrm{VCl}$ ) are anomalously low, but low values do not always indicate droughts (Rimkus et al. 2017). Therefore, satellite information is not very suitable for drought identification. However, this could provide additional information on the severity of a drought's impact and its spatial extent.

Droughts can both cover large areas and be local. Analysis of droughts from 1950 to 2012 found that northern Europe and Russia had the strongest, longest and most frequent droughts in the 1950s, Central Europe and the British Isles in the 1970s, and the Mediterranean and Baltic countries in the 1990s (Spinoni et al. 2015). Our research also shows that the highest number of extreme droughts in Lithuania occurred between 1992 and 2006. The IPCC report indicates that there is not enough information to suggest that the increase in the number of droughts was statistically significant on a global scale (IPCC 2014). This is partly due to differences in the concept of drought and the criteria for its identification in different countries. However, long-term tendencies of the number and intensity of droughts vary from one region to another.

It is very likely that the inequality of the distribution of precipitation in Lithuania will increase in the future, especially in the warm period of the year. Thus, droughts and long rainy periods are likely to occur more frequently. Although total annual precipitation is expected to increase in the 21st century in Lithuania, in the second half of summer and early autumn the amount of precipitation will not change or may even decrease (Keršytè et al. 2015). Meanwhile, the air temperature will increase throughout the entire year. As a result, the number as well as intensity of droughts may increase in the future during the period between July and September (Keršytè et al. 2015). Similar results were obtained after the analysis of Al projections for the 21st century (Stonevicius et al. 2018). It should also be noted that winter temperatures are very likely to rise in the future; therefore, the snow depth as well as the number of days with snow cover will decrease. Such tendencies were also observed in recent decades (Rimkus et al. 2018). In addition, the duration and thickness of the frost layer will decrease, making it easier for groundwater to transform into river run-off during winter. Thus, soil moisture reserves formed by snowmelt water will be lower in the spring. Therefore, a much shorter period may be needed in spring to start form a soil moisture deficit. In conclusion, the risk of drought will increase both in spring and in the second half of summer. 
Our suggested methodology for drought identification in Lithuania is not related to the climate norm, and therefore is suitable for the changing climatic conditions. However, the methodology itself neither diminishes nor increases the risk of drought, and therefore it is necessary to take measures to prevent a significant decrease in yield due to the expected rise in drought number and intensity. Choosing the right adaptation measures is perhaps the most important challenge in the context of climate change. On the other hand, climate change is not only a threat but also an opportunity for agriculture.

\section{Acknowledgement}

This research was funded by National Paying Agency under the Ministry of Agriculture of the Republic of Lithuania (MT-19-2). The authors also would like to acknowledge the contribution of the COST Action "Understanding and modeling compound climate and weather events" (DAMOCLES; CA17109).

\section{References}

Beguería, S., Vicente-Serrano, S.M., Reig, F. \& Latorre, B. 2014. Standardized precipitation evapotranspiration index (SPEI) revisited: Parameter fitting, evapotranspiration models, tools, datasets and drought monitoring. International Journal of Climatology 34: 3001-3023. https://doi.org/10.1002/joc.3887

Blain, G.C. 2012. Revisiting the probabilistic definition of drought: strengths, limitations and an agrometeorological adaptation. Bragantia 71: 132-141. https://doi.org/10.1590/s0006-87052012000100019

Bond, N.R., Lake, P.S. \& Arthington, A.H. 2008. The impacts of drought on freshwater ecosystems: An Australian perspective. Hydrobiologia 600: 3-16 https://doi.org/10.1007/s10750-008-9326-z

Byun, H.R. \& Wilhite, D.A. 1999. Objective quantification of drought severity and duration. Journal of Climate 12: $2747-2756$. https://doi.org/10.1175/1520-0442(1999)012<2747:OQODSA>2.0.CO;2

Dalezios, N.R., Blanta, A. \& Spyropoulos, N.V. 2012. Assessment of remotely sensed drought features in vulnerable agriculture. Natural Hazards and Earth System Science 12: 3139-3150. https://doi.org/10.5194/nhess-12-3139-2012

Dexter, A.R. 2004. Soil physical quality: Part I. Theory, effects of soil texture, density, and organic matter, and effects on root growth. Geoderma 120: 201-214. https://doi.org/10.1016/j.geoderma.2003.09.004

Grigorieva, E., Matzarakis, A. \& de Freitas, C. 2010. Analysis of growing degree-days as a climate impact indicator in a region with extreme annual air temperature amplitude. Climate Research 42: 143-154. https://doi.org/10.3354/cr00888

Hargreaves, G.H. \& Allen, R.G. 2003. History and evaluation of hargreaves evapotranspiration equation. Journal of Irrigation and Drainage Engineering 129. https://doi.org/10.1061/(ASCE)0733-9437(2003)129:1(53)

Hossain, A., Teixeira da Silva, J.A., Lozovskaya, M.V. \& Zvolinsky, V.P. 2012. High temperature combined with drought affect rainfed spring wheat and barley in South-Eastern Russia: I. Phenology and growth. Saudi Journal of Biological Sciences 19: 473-487. https://doi.org/10.1016/j.sjbs.2012.07.005

IPCC 2014. Climate Change 2014: Synthesis Report. Contribution of Working Groups I, II and III to the Fifth Assessment Report of the Intergovernmental Panel on Climate Change. Core Writing Team, R.K. Pachauri and L.A. Meyer (eds.). IPCC, Geneva, Switzerland. $151 \mathrm{p}$.

Jamali, S., Seaquist, J.W., Ardo, J. \& Eklundh, L. 2011. Jamali, S., Seaquist, J., Ardö, J., \& Eklundh, L. 2011. Investigating temporal relationships between rainfall, soil moisture and MODIS-derived NDVI and EVI for six sites in Africa. Proceedings of 34th International Symposium on Remote Sensing of Environment - The GEOSS Era: Towards Operational Environmental Monitoring, Sydney, NSW, Australia.

Keršytė, D., Rimkus, E. \& Kažys, J. 2015. Near-term and long-term climate projections for Lithuania. Geologija. Geografija 1: 22-35. (in Lithuanian). https://doi.org/10.6001/geol-geogr.v1i1.3069

Keyantash, J.A. \& Dracup, J.A. 2004. An aggregate drought index: Assessing drought severity based on fluctuations in the hydrologic cycle and surface water storage. Water Resources Research 40: 1-13. https://doi.org/10.1029/2003WR002610

Krueger, E.S., Ochsner, T.E. \& Quiring, S.M. 2019. Development and evaluation of soil moisture-based indices for agricultural drought monitoring. Agronomy Journal 111: 1392-1406. https://doi.org/10.2134/agronj2018.09.0558

Li, Y., Ye, W., Wang, M. \& Yan, X. 2009. Climate change and drought: a risk assessment of crop-yield impacts. Climate Research $39:$ 31-46. https://doi.org/10.3354/cr00797

Lloyd-Hughes, B. 2014. The impracticality of a universal drought definition. Theoretical and Applied Climatology 117: 607-611. https://doi.org/10.1007/s00704-013-1025-7

McKee, T.B., Doesken, N.J. \& Kleist, J. 1993: The Relationship of Drought Frequency and Duration to Time Scales. Proceedings of the 8th Conference on Applied Climatology, 17-22 January 1993, Anaheim, CA. Boston, MA, American Meteorological Society. https://www.droughtmanagement.info/literature/AMS_Relationship_Drought_Frequency_Duration_Time_Scales_1993.pdf

Naumann, G., Spinoni, J., Vogt, J.V. \& Barbosa, P. 2015. Assessment of drought damages and their uncertainties in Europe. Environmental Research Letters 10: 1-14. https://doi.org/10.1088/1748-9326/10/12/124013

Niemeyer, S. 2008. New drought indices. In: López-Francos A. (ed.). Drought management: scientific and technological innovations. Zaragoza: ClHEAM, p. 267-274. (Options Méditerranéennes: Série A. Séminaires Méditerranéens; n. 80). 1. International Conference Drought Management: Scientific and Technological Innovations, 2008/06/12-14, Zaragoza (Spain).

http://om.ciheam.org/om/pdf/a80/00800451.pdf 


\section{AGRICULTURAL AND FOOD SCIENCE}

E. Rimkus et al. (2020) 29: 359-371

Quiring, S.M. \& Papakryiakou, T.N. 2003. An evaluation of agricultural drought indices for the Canadian prairies. Agricultural and Forest Meteorology 118: 49-62. https://doi.org/10.1016/S0168-1923(03)00072-8

Rimkus, E., Briede, A., Jaagus, J., Stonevičius, E., Kilpys, J. \& Viru, B. 2018. Snow-cover regime in Lithuania, Latvia and Estonia and its relationship to climatic and geographical factors in 1961-2015. Boreal Environment Research 23: $193-208$.

Rimkus, E., Stonevicius, E., Kilpys, J., Maciulyte, V. \& Valiukas, D. 2017. Drought identification in the eastern Baltic region using NDVI. Earth System Dynamics 8: 627-637. https://doi.org/10.5194/esd-8-627-2017

Rimkus, E., Stonevičius, E., Korneev, V., Kažys, J., Valiuškevičius, G. \& Pakhomau, A. 2013. Dynamics of meteorological and hydrological droughts in the Neman river basin. Environmental Research Letters 8: 1-10. https://doi.org/10.1088/1748-9326/8/4/045014

Rimkus, E., Valiukas, D., Kažys, J., Gečaite, I. \& Stonevičius, E. 2012. Dryness dynamics of the Baltic Sea region. Baltica 25: $129-142$. https://doi.org/10.5200/baltica.2012.25.13

Selyaninov, G.T. 1928. About climate agricultural estimation. Proceedings on Agricultural Meteorology 20:165-177.

Spinoni, J., Naumann, G., Vogt, J.V. \& Barbosa, P. 2015. The biggest drought events in Europe from 1950 to 2012 . Journal of Hydrology: Regional Studies 3: 509-524. https://doi.org/10.1016/j.ejrh.2015.01.001

Stonevičius, E., Rimkus E., Kažys, J., Bukantis, A., Kriaučiūienė, J., Akstinas, V., Jakimavičius, D., Povilaitis, A., Ložys, L., Kesminas, V., Virbickas, T. \& Pliūraitè, V. 2018. Recent aridity trends and future projections in the nemunas river basin. Climate Research 75 : 143-154. https://doi.org/10.3354/cr01514

Vicente-Serrano, S.M., Beguería, S. \& López-Moreno, J.I. 2010. A multiscalar drought index sensitive to global warming: The standardized precipitation evapotranspiration index. Journal of Climate 23: 1696-1718. https://doi.org/10.1175/2009JCLI2909.1

Wanders, N., Van Loon, A.F. \& Van Lanen, H.A.J. 2017. Frequently used drought indices reflect different drought conditions on global scale. Hydrology and Earth System Sciences Discussions. https://doi.org/10.5194/hess-2017-512

Wilhite, D.A. \& Glantz, M.H. 1985. Understanding: The drought phenomenon: The role of definitions. Water International 10: 111-120. https://doi.org/10.1080/02508068508686328

WMO 2012. Standardized Precipitation Index User Guide (M. Svoboda, M. Hayes \& D. Wood). (WMO-No. 1090), Geneva. https://library.wmo.int/doc_num.php?explnum_id=7768

WMO \& GWP 2016. Handbook of Drought Indicators and Indices (M. Svoboda and B.A. Fuchs). Integrated Drought Management Programme (IDMP), Integrated Drought Management Tools and Guidelines Series 2. Geneva. https://library.wmo.int/doc_num.php?explnum_id=3057

Zargar, A., Sadiq, R., Naser, B. \& Khan, F.I. 2011. A review of drought indices. Environmental Reviews 19: 333-349. https://doi.org/10.1139/a11-013

Zribi, M., Paris Anguela, T., Duchemin, B., Lili, Z., Wagner, W., Hasenauer, S. \& Chehbouni, A. 2010. Relationship between soil moisture and vegetation in the Kairouan plain region of Tunisia using low spatial resolution satellite data. Water Resources Research 46: 1-13 https://doi.org/10.1029/2009WR008196 